\title{
Marxismo analítico: ¿una alternativa a la crisis teórica del marxismo
}

"Que yo sepa, no es que todos los hegelianos sean pedantes, pero de algún modo pienso que todos los pedantes tendrian que acabar siendo hegelianos".

William James, Ensayos sobre el empirismo radical, 1903-1904

\section{Introducción}

1 1 fin del milenio se ve acompañado de la crisis de los paradigmas teóricos $\mathrm{y}$ políticos que orientaron la praxis del hombre occidental a lo largo del siglo XX. Vivimos en una época de transición en la que se han derrumbado las grandes certezas sociales, económicas, políticas y filosóficas que alimentaron a occidente desde el advenimiento de la modernidad, y en la que no emergen nuevas certezas y seguridades. Vivimos en un época en la que "todo lo sólido se desvanece en el aire" (K. Marx, M. Bermann).

El marxismo no ha escapado a esta suerte. Por un lado, sus supuestos fundamentales como proyecto social y político entraron en una crisis quizás irreversible con el colapso de los socialismos reales. Por otro, como teoría social y económica, ha mostrado importantes limitaciones, que exigen no sólo un reexamen a fondo del pensamiento de Marx y de la tradición marxista, sino una reformulación de muchas de las tesis que se consideraron inamovibles incluso en el marco de la coyuntura teórico-política suscitada por la perestroika y la glasnot.

Es casi imposible no aceptar que el fin de siglo encuentra al marxismo immerso en una severa crisis histórica y teórica. $Y$, sin que exista una 
rígida relación de causalidad entre ambas, es inobjetable que la primera -expresada en el colapso de los socialismos reales y la creciente pérdida de legitimidad del proyecto socialista - ha llevado a la revisión del corpus teórico marxista, revisión que ha mostrado que muchas de sus inconsistencias teóricas provienen del supuesto indiscutido hasta hace muy poco de que el marxismo se validaba teóricamente por su eficacia política. Una vez mostrada la ineficacia socio-política y económica del proyecto socialista - tal y como éste se plasmó en los socialismos reales- queda en pie el examen de su consistencia teórica en cuanto tal. ¿El colapso de los socialismos reales supone el colapso del corpus teórico marxista? ¿O acaso el fracaso del socialismo real es absolutamente independiente del paradigma marxista?

Los que optan por una respuesta positiva para la primera pregunta, parten de una identificación entre los postulados teóricos del marxismo y la concreción histórica del proyecto socialista. Para éstos, los supuestos logros que obtuvo el socialismo soviético desde 1917 hasta antes de su colapso definitivo en 1989 constituían no sólo la prueba irrefutable de su superioridad como modelo socio-económico y político sobre el modelo capitalista, sino la verificación "científica" de los postulados teóricos de Marx, Engeles y Lenin, codifificados dogmáticamente en el "materialismo histórico" y el "materialismo dialéctico". Colapsado el modelo socialista soviético, los partidarios de una interpretación como la señalada no tendrían más alternativa, si son consecuentes con las premisas de su argumentación, que aceptar el fracaso teórico del marxismo.

Quienes optan por una respuesta positiva para la segunda pregunta, son los que sostendrían no sólo que entre el socialismo real y las formulaciones teóricas del marxismo no existiría vínculo alguno, sino que el socialismo real habría fracasado justamente por haberse construído de espaldas al proyecto teórico de Marx. Aquí se estaría aceptando no tanto le necesidad de medir la consistencia teórica del discurso marxista apelando a su eficacia práctica, sino la necesidad de medir la legitimidad y consistencia del proyecto histórico socialista a partir de su "fidelidad" a los lineamientos teóricos -filosóficos, económicos y políticos- del marxismo. Si el socialismo real fracasó — se nos viene a decir- fue por su traición al verdadero marxismo, o peor aún por su anti-marxismo.

Por tanto, si para los primeros con el derrumbe del socialismo soviético se vinieron abajo también los logros teóricos del marxismo, para los segundos el colapso de los socialismos reales deja inalterada la verdad de los postulados marxistas e incluso los fortalece no sólo en cuanto que muchos rasgos de la crisis del socialismo real fueron diagnosticados primero que nadie por marxistas fieles al espíritu de Marx, sino en tanto 
que la misma vino a corrobar, por la vía de la imposibilidad, las tesis de Marx acerca de las condiciones históricas para la construcción de socialismo.

De cualquier modo, no cabe duda de que el marxismo ha caído en una severa crisis no sólo histórica, sino teórica. Y las propuestas alternativas para afrontar la crisis en sus diferentes niveles no se han hecho esperar. La formulación de un proyecto de "socialismo posible" (L. Paramio, N. Bobbio), en el que se restituya el componente democrático como algo consustancial al socialismo, o el relanzamiento del proyecto socialdemócrata como alternativa al modelo de socialismo soviético, constituyen las respuestas más importantes a la crisis del marxismo como proyecto histórico. Asimismo, para afrontar la crisis teórica del marxismo, se han abierto varios frentes, ya sea para "rescatar" del marxismo su componente ético, para "recuperar" algunos aspectos de su teoría económica o para refundar sus bases metodológicas.

Uno de los más recientes esfuerzos en esta última dirección lo constituye el realizado por autores cercanos a lo que se conoce como marxismo analítico (J. Elster, A. Przeworski, R. Brenner, G. A. Cohen...). ¿Qué es el "marxismo analítico"? ¿Cuáles son sus tesis principales? ¿Cuál es su interpretación del marxismo? ¿Constituye una alternativa teórica a la crisis teórica del marxismo? Son justamente estas interrogantes las que orientan el presente ensayo, cuyo objetivo fundamental es instroducir elementos para animar el debate en torno a la necesaria redefinición del marxismo, redefinición que pasa antes que nada por la aceptación de la gravedad de su crisis teórica e histórica.

\section{Caracterización del "marxismo analítico"}

\subsection{La centralidad del método}

Ante todo, hay que señalar que el marxismo analítico tiene como propósito distanciarse del marxismo "tradicional" centrándose más en cuestiones de naturaleza metodológica, y menos en cuestiones que atañen al diagnóstico elaborado desde un horizonte marxista sobre una coyuntura histórica particular o a la aplicación política que se podría derivar de dicho diagnóstico. Esta apuesta por la metodología marxista tiene como trasfondo la apuesta por el carácter científico del marxismo, así como por la necesidad de validarlo teóricamente, según algunos de los criterios científicos vigentes en la actualidad. De este modo,

"quienes lo práctican [el marxismo analítico] se encuentran profundamente inspirados por las temáticas del marxismo e intentan abordar- 
las mediante algunas herramientas contemporáneas de disciplinas como la lógica y la matemática así como de la construcción de modelos. Su postura metodológica es académica. Se reconocen, de modo consciente, resultado de las tradiciones marxista y no marxista"1.

La apelación a la lógica y a la matemática no es gratuita: el acento en la metodología como elemento central del quehacer científico se inspira, en los cultivadores del tipo de marxismo que examinamos, en la tradición de pensamiento analítico, misma que ha dado lugar tanto al positivismo lógico de Russell, Reichenbach y Ayer ${ }^{2}$ y como al racionalismo crítico de Popper y Hans Albert3. Para estas dos escuelas, pero más explícitamente para los segundos, la ciencia es el método, es decir, el "ensayo de solución" implementado en cada investigación particular, y no la teoría como sugiere en parte el mismo Popper o la tradición hermenéutica y la teoría crítica.

Esta reducción de la ciencia al método lleva a sus portavoces no sólo a formular una teoría unificada del método - con la que se pretende dejar establecido un único método de investigación válido tanto para las ciencias naturales como para las ciencias sociales-, sino que los lleva a identificar la objetividad científica con la objetividad del método. Como señala Popper: "la llamada objetividad de la ciencia radica en la objetividad del método crítico; lo cual quiere decir, sobre todo, que no hay teoría que esté liberada de la crítica, y que los medios lógicos de los que se sirve la crítica - la categoría de contradicción lógica-son objetivos" 4 .

Los marxistas analíticos se inscriben, pues, en una tradición intelectual que tiende a identificar ciencia y método, método y objetividad. Se trata, asimismo, de una tradición que apuesta por la formulación de un método único para la investigación de los diversos ámbitos del saber y la realidad. Este método único ha de estar fundamentado, como no puede ser para menos, en el procedimiento investigativo seguido por las ciencias naturales, cuyo estatuto "científico" pocos se atreverían a poner en duda.

De aquí no sólo la apelación a la lógica, la matemática y la construcción de modelos, sino la asunción de una serie de compromisos teóricos que caracterizan el trabajo de sus partidarios, y que, siguiendo a Roemer, podemos resumir así: a) "una responsabilidad irrestricta hacia la necesidad de abstracción", con lo cual se distancian del marxismo tradicional que "vacila cuando se aleja demasiado de la historia real"; b) "la búsqueda de fundamentos", que pretende resolver cuestiones que el marxismo tradicional no considera indispensable formular como, por ejemplo: " $¿$ Por qué emergen las clases sociales como actores colectivos importantes?" ¿Tiene el socialismo algún atractivo para los trabajadores en el capitalismo moderno?" “¿Es la igualdad una meta de la ética marxista"?; c) la acepta- 
ción del "éxito desigual del socialismo y el dudoso fracaso de capitalismo", cuestiones que constituyen "incuestionablemente los enormes retos del marxismo, tal como se heredó de su forma original en el siglo XIX"; d) reconocimiento de que "el marxismo es una ciencia social que nace durante el siglo XIX. Como tal, está sujeto a ciertas limitaciones: es primitivo frente a los estándares modernos y resulta equivocado tanto en algunos detalles como incluso, tal vez, en ciertos argumentos esenciales"; e) "enfoque no dogmático del marxismo", lo cual se expresa en la poca exégesis marxista y la poca preocupación "por lo que Marx dijo o escribió". Lo que importa "es la coherencia de su pensamiento"5.

Dicho lo anterior, se pregunta Roemer: "¿por qué debe llamarse marxista este tipo de esfuerzo?".

"No estoy seguro de que así deba ser - responde inmediatamente este autor-, aun cuando la etiqueta sí conlleva por lo menos ciertas introspecciones fundamentales que se consideran provenientes de Marx. El materialismo histórico, las clases sociales y la explotación son tratadas como categorías centrales en la organización de las ideas. Existe la creencia de que alguna forma de socialismo es superior al capitalismo actual y de que la alienación e injusticia del capitalismo contemporáneo pueden ser superados en ese tipo de socialismo. En realidad, probablemente la mayor tarea del marxismo de hoy sea construir una teoría moderna del socialismo. Tal teoría debe incluir una explicación de las ineficiencias e injusticias del capitalismo moderno, así como un proyecto teórico para esas fallas en una sociedad socialista factible. Creo que los métodos y herramientas del marxismo analítico son lo que se requiere para elaborar tal teoría"6.

La formulación de una teoría moderna del socialismo es, pues, uno de los objetivos fundamentales del marxismo analítico. Para elaborar esa teoría, así como para que la misma pueda gozar de un estatuto científico acorde con los estándares modernos del quehacer científico, se requiere, como se desprende de lo dicho arriba, de una fundamentación del método marxista, misma que supone no sólo una asimilación del instrumental lógico-matemático, sino un crítica radical de los supuestos metodológicos del marxismo tradicional. Esta crítica -formulada explícitamente por autores como Jon Elster- no sólo permite establecer con mayor claridad la intencionalidad teórica del marxismo analítico, sino establecer la asunción que hacen muchos de sus partidarios, particularmente autores como el mismo Elster, Michael Taylor o Adam Pzeworski7, de elementos importantes de la otra gran tradición metodológica occidental, como lo es el "individualismo metodológico" de raíces weberianas8. 


\subsection{El "individualismo metodológico" y la metodología del "marxis- mo tradicional"}

La ciencia económica, con su énfasis puesto en el paradigma del intercambio, así como en el supuesto de la maximización de las funciones de utilidad como algo característico de los agentes económicos, ha lanzado el desafío de "basar todas las teorías de la sociedad en las acciones racionales de los invidividuos orientadas hacia un fin" 9 . El "individualismo metológico" responde a ese desafío lanzado por la economía al conjunto de las ciencias sociales, y su punto de partida metodológico es que "el hombre es un ser de elección racional" (R. Benjamin), por lo cual "el comportamiento humano puede ser explicado en términos de elección racional... La teoría de la elección racional supone que la gente elegirá el curso de acción preferido que considere mejor... la acción que piensa mejor se adapta a sus propósitos"10. ¿Y cuando es que una acción humana puede ser considerada racional? Cuando "i) puede justiticarse como la mejor manera de llevar acabo los deseos del agente, dadas sus creencias, ii) dichas creencias pueden justificarse por las pruebas que tiene disponibles, y iii) el monto de evidencia recogida por el agente puede explicarse en términos de sus deseos y de las limitaciones sobre la información disponible"11.

A partir del supuesto metodológico de que los individuos humanos son seres de elección racional, el "indidivualismo metodológico" afirma que "todas las instituciones, pautas de comportamiento y procesos sociales pueden ser explicados, en principio, en términos de los individuos únicamente: de sus acciones propiedades y relaciones"12. Ello implica una apuesta por los microfundamentos, dejando de lado las perspectivas totalizantes o estructurales en el análisis de la realidad social y asumiendo que la reducción de los procesos sociales "es una estrategia esencial de la ciencia" (J. Elster).

Desde el horizonte del "individualismo metodológico", Elster rechaza los elementos metodológicos que, en su opinión, constituyen premisas fundamentales del marxismo tradicional: "primero, el holismo metodológico, la opinión de que en la vida social existen totalidades o colectividades, irreducibles a enunciados sobre los miembros individuales. Segundo, la explicación funcional, el intento de explicar los fenómenos sociales en términos de sus consecuencias beneficiosas, para alguien o para algo... El tercero es la deducción dialéctica, una manera de pensar derivada de la lógica de Hegel"13.

Según Elster, las dos primeras premisas no son exclusivas de la elaboración teórica marxista, sino que se encuentran separadas o combinadas en la ciencia social no marxista, como por ejemplo en los trabajos de 
Emile Durkheim o Robert Merton14. La novedad de Marx estriba tanto en la integración metodológica de la tercera premisa - "el elemento hegeliano a vaces sobreañadido"-, como en la "naturaleza de las totalidades y los beneficios que entran en la explicación"15. Es este último elemento el que le permite utilizar la explicación funcional "no sólo para dar cuenta de la estabilidad de las sociedades, sino también para demostrar la tendencia inherente en ellas hacia el comunismo" 16 .

En definitiva, la presencia en el marxismo de las premisas metodológicas arriba señaladas hacen impresicindible aceptar que

"Marx fue una figura muy del siglo XIX, es decir, en cuestiones metodológicas, una figura de transición. Liberado de las suposiciones teológicas explícitas, conservó la perspectiva teológica inspirada por ellas. Como la mayoría de sus contemporáneos, quedó impresionado por el progreso de la biología, y erróneamente pensó que el estudio de la sociedad podía beneficiarse del estudio de los organismos (....). Su cientificismo - la creencia en 'leyes del movimiento' de la sociedad que operan con una 'necesidad de hierro'- descansaba en una extrapolación ingenua de los logros de la ciencia natural. Encontraremos a cada paso que las concepciones metodológicas trasnochadas coexisten en su obra con sorprendentes y frescas intuiciones" 17.

Estas "soprendentes y frescas intuiciones" contituyen la veta en la cual hay que buscar los elementos que conectan a Marx con las ciencias sociales contemporáneas, sobre todo las que han asumido los supuestos del "individualismo metodológico". De acuerdo con Elster, rastrear esos elementos supone reconocer que si bien en Marx se haya presente el holismo metodológico - especialmente en su consideración del capital como una entidad colectiva y en su consideración de la Humanidad como un sujeto colectivo-, ese horizonte metodológico no impidió que la mayor parte del tiempo Marx se ocupara "en general de los lazos que se forjan entre motivos individuales, comportamiento individual y consecuencias agregadas"18. Es decir, a Marx no le era ajena la perspectiva de los individuos, especialmente en lo que se refiere a su realización en la sociedad futura, en el comunismo. "El atractivo del comunismo, a sus ojos, era permitir la autorrealización de cada uno y de todos los individuos, no sólo de una élite pequeña. Como un producto lateral, habría también un florecimiento sin precedentes de la humanidad" 19.

Por consiguiente, si en los análisis de Marx es posible rastrear elementos que podrían ser compatibles con el individualismo metodológico -específicamente, elementos en los que se resalta la importancia de los individuos para la comprensión de los procesos sociales-, ello indicaría que es posible rastrear en el pensamiento marxiano elementos que lo 
hagan compatible con las perspectivas de la elección racional. Eso es lo que examinaremos a continuación.

\subsection{Marxismo y elección racional}

En opinión de Adam Przeworski, la ciencias sociales vienen sufriendo desde la década de los 80 una ofensiva proveniente del ámbito de la economía, misma que consistiría en la imposición del monopolio del método económico en todos los estudios de la sociedad20. El resultado más notable de este proceso consistiría en la redefinición de los paramétros para explicar el comportamiento humano: éste puede ser explicado en términos de elección racional individual, y no ya -como se ha hecho tradicionalmente- en términos de su facultad de razón. Este desplazamiento de la facultad de razón hacia la esfera de las acciones individuales supone una reducción del homo sapiens al homo ecomicus, el cual no se diferencia en lo absoluto del homo politicus y del homo sociologicus.

Con esta reducción, el ser humano pasa a ser explicado como una realidad cuyo comportamiento individual obedece a las reglas de la economía, más específicamente, a las reglas del mercado. Como señala Elster,"la teoría de la elección racional supone que la gente elegirá el curso de acción preferido o que considera mejor. Elegir racionalmente es elegir la mejor acción del conjunto factible"21. Y "elegir la mejor acción del conjunto factible" no es más que buscar maximizar los beneficios cada vez que se elige, minimizando los costos. Entendido así, el individuo humano no sólo se caracteriza por ser un maximizador y calculador, sino que el eje de sus decisiones lo constituye su propio interés individual.

Esto último ha llevado a los defensores de la teoría de la elección racional a plantearse el problema de la compatibilidad o incompatibilidad entre las elecciones individuales -en las que priva la perspectiva maximizadora individual - y las elecciones colectivas -en las que muy probablemente los beneficios colectivos supongan un desplazamiento de los beneficios individuales-. Este problema es enfrentado a partir de la teoría de los juegos, a la que recurren los defensores de la elección racional en búsqueda de una alternativa analítica que permita comprender las complejas articulaciones existentes entre los intereses individuales y los intereses colectivos.

Elster afirma lo siguiente sobre la teoría de los juegos:

"Soy de los que creen que esta teoría ofrece un marco conceptual unificador para la mayoría de las ciencias sociales, pues nos capacita para tres tipos de interdependencia que penetran la vida social. Pri- 
mero, el hecho de que la recompensa de cada uno depende de las recompensas de todos, por altruismo, envidia y cosas así; segundo, el hecho de que la recompensa de cada uno depende de las elecciones de todos, mediante la causalidad social general; y tercero, el hecho de que la elección de cada uno depende de las elecciones de todos mediante anticipación y cálculo estratégico"22.

Estas interacciones sociales ciertamente no se concretan en cada acción social específica, sino que constituyen, en el horizonte de la teoría de los juegos, posibilidades conceptuales, no necesidades (J. Elster). Un ejemplo de estas posibilidades conceptuales lo constituye el dilema del prisionero, que es uno de los casos preferidos para demostrar las virtudes analíticas de la teoría de los juegos. Elster ejemplifica, apelando a una situación de huelga, el dilema del prisionero:

"Supongamos que cada obrero tiene que elegir entre dos opciones: ir a la huelga o abstenerse. Supongamos, además, que para todos los trabajadores es mejor ir todos a la huelga que no ir ninguno, porque en el primer caso pueden presionar con éxito por un aumento de salario. Supongamos finalmente que los obreros están únicamente motivados por las ganancias materiales y personales. Entonces, para cada obrero será siempre mejor abstenerse, independientemente de lo que hagan los demás. Si los otros van a la huelga, éste puede actuar como francotirador* y obtener el aumento de salario sin el riesgo y los costes de la huelga, y si los otros no van a la huelga, no tiene sentido una acción unilateral de solidaridad. En consecuencia, el que actúa individualmente no irá a la huelga; tampoco irán los otros porque están en una situación similar. Debido a que todos los obreros actúan de forma individualmente racional, el resultado obtenido es peor para todos de lo que podía haber sido si hubieran sido capaces de cooperar" 23 .

Como podemos ver, en las elecciones individuales - de las cuales las elecciones que hacen los obreros ante una situación de huelga constituyen un caso entre muchos otros- se entrelazan redes de intereses, espectativas y motivos cuya complejidad es necesario desentrañar si lo que se pretende es explicar la lógica de las acciones colectivas; y, para ello, la teoría de la elección racional y la teoría de los juegos constituyen importantes instrumentos analíticos y conceptuales. En este sentido, teo-

* "Francotirador" es una de las acepciones que se puede dar a la palabra "free rider" (el que "viaja gratis"), utilizada por Jon Elster para definir la situación descrita en el texto. Una mejor acepción castellana es la de "gorrón", es decir, de aquel que se beneficia de los esfuerzos realizados por los otros en una acción conjunta sin participar del esfuerzo común y sin correr los riegos que ello supondría. 
rías sociales interesadas en el análisis de las acciones colectivas como el marxismo podrían, en opinión de los defensores del marxismo analítico, obtener muchos beneficios del potencial analítico y conceptual que encierran las teorías aludidas.

\subsection{La superación del "estructuralismo"}

Ahora bien, la asunción de la perspectiva de la elección nacional y de la teoría de los juegos por el corpus teórico marxista implica la superación de algunas de las resistencias que se derivan de los supuestos metodológicos "estructuralistas" presentes en el pensamiento de Marx. Estos supuestos metodológicos habrían llevado a Marx a negar que los trabajadores y los empresarios fueran agentes en el sentido absoluto del término, es decir, "personas que eligen activa y libremente", sino que son más bien "meros ocupantes de un lugar o, en sus propias palabras 'máscaras de naturaleza económica' condenadas a actuar según la lógica del sistema capitalista"24. Esto daría pie para negar la importancia de las elecciones individuales de capitalistas y obreros, quienes se verían forzados a comportarse según lo exigiera la fuerza de las circunstancias: los primeros, se ven forzados por la competencia a actuar como lo hacen ya que de lo contrario serían barridos del mercado, mientras que los segundos se ven forzados no sólo a vender su fuerza de trabajo, sino a restringir su consumo por los bajos salarios (J. Elster).

En la perspectiva de Marx, la negación de la elección por parte de los agentes económicos está estrechamente ligada, como reconoce Elster, a la teoría del valor-trabajo, según la cual la economía tiene una "estructura superficial" y una "estructura profunda". En palabras de este autor, "la estructura superficial es la vida económica cotidiana, en la que los agentes económicos realizan acciones racionales en términos de los precios del mercado de mercancías. En la estructura profunda, las mercancías se caracterizan por sus valores trabajo: la cantidad de tiempo de trabajo socialmente necesaria para su producción. La estructura superficial es simplemente la realización de las relaciones definidas por la estructura profunda, exactamente igual que la apariencia visible de un objeto físico es una mera consecuencia de su estructura atómica" 25.

Para Elster, esa contraposición entre precios y valores, vistos como la esencia y la apariencia de la vida económica, no es sólo escasamente inteligible $\mathrm{y}$ un impedimento que no permitió a Marx apreciar la centralidad de las elecciones y alternativas en la economía, sino que la misma no afectó sus análisis concretos, en los "cuales Marx reconoce totalmente la sutil interrelación entre elección empresarial, beneficio, tecnología y poder en la empresa. Su sociología política, asimismo, fue sen- 
sible al pensamiento racional y estratégico por parte de los agentes principales"26. Es decir, a Marx no le fue ajena la perspectiva de la elección racional, así como las complejas relaciones en que se fusionan las elecciones individuales de agentes de clase distintos. Se trata, pues, de reconcer este hecho, y de reconstruir la teoría marxista a la luz de la teoría de la elección racional, muchos de cuyos elementos no son ajenos al planteamiento marxista. Ello supone, como hemos visto, superar el horizonte estructuralista en que se mueven las investigaciones macrohistóricas de Marx, pero también supone superar dos obstáculos adicionales: la explicación funcional y la dialéctica27.

\subsection{La superación de la "explicación funcional" y la "dialéctica"}

La explicación funcional es distinta tanto de la explicación causal -en la cual de da cuenta de un fenómeno estableciendo su causa efectivacomo de la explicación intencional — de la cual la explicación de la elección racional es la más importante de todas (J. Elster)-, y se caracteriza por apelar a la consecuencia del fenómeno para dar cuenta del mismo. "Marx, por ejemplo — señala Elster-, explica la movilidad social ascendente señalando los beneficios que la clase capitalista obtiene de un flujo continuo de nuevos miembros" 28 . Sin embargo, este mismo autor hace notar lo siguiente: "el enigma es cómo un suceso puede ser explicado por otro suceso que ocurre en un tiempo posterior. Tiene que haber una explicación para el suceso cuando éste ocurre: no puede ser necesario tener que esperar a las consecuencias para explicarlo" 29 .

En cierto modo, pues, la explicación funcional supone un nexo de retro-alimentación, es decir, una "conexión causal desde las consecuencias de un suceso del tipo que tratamos de explicar, hasta otro, un suceso posterior del mismo tipo"30. Esta explicación ciertamente puede ser útil cuando, por ejemplo, "un patrón de comportamiento se conserva a través de las consecuencias que genera" 31 . Sin embargo, la validez de la explicación funcional tiene sus peligros; y ello sucede cuando: a) es utilizada para explicar - como sucede en la filosofía de la historia de Marx"sucesos singulares no recurrentes en términos de consecuencias no intencionadas"; y b) cuando se explica funcionalmente un hecho social en el cual el nexo de retro-alimentación "no está demostrado, sino sólo postulado o supuesto tácitamente" 32 .

En definitiva, la explicación funcional, tal como es utilizada por el marxismo, se centra en las consecuencias beneficiosas que puede generar determinado comportamiento de clase - ya sea para la dominación capitalista, la integración social o el bienestar obrero- para dar por concluída la comprensión del comportamiento en cuestión. Ello lleva no sólo a ob- 
viar la investigación de los mecanismos mediante los cuales los intereses individuales y colectivos generan o sostienen políticas, sino a pasar de largo ante la posibilidad de que los beneficios pudiesen ser puramente accidentales $y$, por tanto, no explicativos (J. Elster).

La "dialéctica" también plantea obstáculos importantes al intento de vincular el marxismo con la elección racional. Para entender cómo ello puede ser así, es conveniente traer a cuenta que el término "dialéctica" supone una distinción básica: la dialéctica como método y la dialéctica como proceso, es decir, "la dialéctica como rasgo de nuestro pensamiento sobre el mundo y la dialéctica como rasgo del mundo mismo"33. Esa distinción, por supuesto, no indica que entre ambas nociones de dialéctica no exista una cierta relación; más aún, en el caso de autores marxistas extremadamente hegelianizados entre ambas existiría una complementariedad: la dialéctica del pensamiento sería "reflejo" de la dialéctica de la realidad. En qué consisten tanto el método dialéctico como la dialéctica de la realidad?

"Podremos definir entonces el método dialéctico - señala J. Elstercomo un procedimiento en el que, a fin de llegar a la verdad de una cuestión, nos vamos, lenta y pacientemente, refinando concepciones anteriores, desechando lo que es erróneo, conservando lo que es correcto y agregando lo que falta. Más bien vamos de un extremo a otro descartando lo que es válido en la postura anterior junto con lo que debe ser propiamente descartado. En una tercera fase podremos alcanzar una postura más equilibrada, pero sólo porque hemos pasado a través de los extremos" 34 .

Y la lógica que rige el método dialéctico no es otra que la de la tesis, antitesis y sintesis, o su equivalente que es la afirmación, negación de la afirmación y negación de la negación. Por lo demás, lo importante de destacar en este punto es que como resultado de este procedimiento se accede a la verdad de las cosas, es decir, a la conceptuación correcta de su naturaleza, que por supuesto es dialéctica. Porque justamente la dialéctica del conocimiento - la lógica dialéctica - tiene como correlato la dialéctica de la realidad. Hegelianos y marxistas se dan la mano en este punto: los procesos dialécticos del mundo atraviesan por fases similiares a las del método dialéctico.

"El ejemplo más importante de proceso dialéctico de Hegel y Marx --señala J. Elster- es probablemente la siguiente secuencia de tres pasos... La sociedad, sostienen ellos, comienza como comunidad primitiva indiferenciada, las personas son esencialmente similiares unas a otras, sin rasgos de carácter disitintivos o funciones productivas diferentes. La comunidad domina al individuo, que queda con pocas 
posibilidades para elegir libremente o para la autorrealización individual. La fase siguiente, negación de la primera, ocurre con el surgimiento de la alienación (Hegel) o de las sociedades de clase (Marx). Está caracterizada por un desarrollo extremo de la individualidad y por una igualmente extrema desintegración de la comunidad. La tercera fase, negación de la negación, restaura la comunidad pero sin destruir la individualidad. En este aspecto es la síntesis de las dos fases previas" 35 .

En opinión de autores como Elster, la concepción de la realidad y el conocimiento, tal y como la acabamos de describir, no sólo arraigó poderosamente en la mente de Marx, sino que "configuró su interpretación de la historia mundial, su concepción de la lucha política y de la táctica, su representación de la sociedad comunista" 36 . Sin embargo, lo peor de todo es que esta concepción "esta relacionada tanto con el holismo metodológico como con la explicación funcional, y comparte, en consecuencia, las deficiencias de ambas" 37 .

Pero, además de compartir las deficiencias del holismo metodológico -incapacidad de acceder a los mifrofundamentos de los procesos sociales-y de la explicación funcional -apelar a las consecuencias de un proceso para explicarlo-, la dialéctica posee, para los marxistas analíticos, otras limitaciones importantes. En primer lugar, no está claro que exista un "vínculo real entre la negación de la negación como un rasgo de los procesos del pensamiento y la negación de la negación como un rasgo de los procesos históricos"; segundo, "la dialéctica no ofrece un método operacional que pueda aplicarse bajo promesa de buenos resutados, dentro de límites bien definidos, y tampoco produce leyes sustantivas del desarrollo histórico con predicciones para casos concretos"; tercero, el lenguaje dialéctico es confuso, y consiste en "ideas tan vagas como sugestivas, que no ofrece instrumentos científicos con filo analítico"; $y$, finalmente, la dialéctica hegeliano-marxista ha olvidado que "los conceptos no tienen una 'lógica del desarrollo' independientemente de las acciones que los hombres llevan a cabo con propósitos particulares" 38 .

En definitiva, el marxismo analítico, al asumir aspectos fundamentales de la teoría de la elección racional, del individualismo metodológico y de la teoría de los juegos, no sólo reivindica la centralidad del método por encima de los elementos filosóficos o doctrinarios que caracterizaron al marxismo tradicional, sino que pone en cuestión supuestos que parecieran inamovibles para la tradición marxista, como el holismo metodológico, la explicación funcional y la dialéctica. Por tanto, el marxismo analítico supone la renuncia a elementos centrales de la interpreta- 
ción marxista tradicional, así como la propuesta de una nueva interpretación del marxismo. ¿Cuáles son elementos a los que habría que renunciar? ¿Cuál es el eje fundamental de la nueva interpretación? ¿Constituye esta nueva interpretación una alternativa a la crisis teórica del marxismo?

\section{Elster: "¿qué vive y qué está muerto de Marx?"}

Ante todo, la pregunta por lo que está muerto de Marx no es occiosa. Siguiendo a Elster, podemos argumentar tres razones para que ello sea así: primero, porque una teoría que se formuló hace cien años, aún cuando fuese correcta en su momento, no puede ser aplicable hoy en día, si es que ha de tomarse en serio la historicidad del conocimiento científico que el mismo Marx tanto propugnó. Segundo, que una teoría haya demostrado limitaciones importantes, incluso en el momento de ser formulada, no debe atribuirse a limitaciones personales de su autor, dados los datos y las técnicas disponibles en la época. Y tercero, no es absurdo asumir que una teoría pueda y deba ser rebasada por desarrollos técnicos y analíticos posteriores, lo cual no obsta para aceptar que esa teoría haya sido lo más avanzado en su momento39.

Por tanto, aceptar que algunos algunos aspectos, incluso sustantivos, del corpus teórico de Karl Marx están muertos supone aceptar tanto la historicidad de su pensamiento, como las limitaciones conceptuales, personales y técnicas propias incluso de los hombres más geniales de la historia del pensamiento, entre lo cuales, sin duda alguna, se encuentra Marx. Dicho ésto, ¿qué está muerto de Marx y qué está vivo?

Para Elster, cuatro son elementos del marxismo que se tendrían que dar por muertos: a) El socialismo científico. "No existe ningún argumento intelectualmente respetable para la opinión de que la historia está sujeta a un patrón progresivo que pueda ser detectado en el pasado y extrapolado al futuro"; b) El materialismo dialéctico. "Las 'leyes de la dialéctica' enunciadas por Engels son algo menos que vacuas, aunque están lejos de ser leyes en el sentido ordinario del término... El término 'materialismo' no sirve para ningún propósito útil"; c) La teleología y el funcionalismo. "La teleología explica todo por conexiones regresivas.., la ciencia procede por conexiones progresivas, desde la causa al efecto". Por otra parte, las explicaciones funcionales no "son necesariamente falsas, sino que Marx no nos da razones para pensar que son verdaderas"; y d) La teoría de las fuerzas productioas y las relaciones de producción. "La objeción principal a la opinión de que las relaciones de propiedad ascienden y caen según su tendencia a promover o trabar el desarrollo de las fuerzas productivas es que no tiene ningún microfundamento. Marx no 
explica cómo la tendencia se convierte en una fuerza social, sostenida por las motivaciones de los hombres individuales" 40 .

Siguiendo nuevamente a Elster, lo vivo de Marx se puede resumir en seis aspectos: a) El método dialéctico, o al menos una versión de él. "Lo que Marx denomina contradicciones sociales corresponde tanto a un cierto de falacia lógica (...), como a los mecanismos perversos mediante los cuales el comportamiento individual racional genera resultados colectivamente desastrosos"; b) La teoría de la alienación y, correlativamente, la concepción de Marx de la buena vida para el hombre. "El énfasis en la autorrealización del individuo excluye cualquier concepción que se centre en la autorrealización de la humanidad. Aunque el compromiso de Marx con el individualismo metodológico fue, en el mejor de los casos, intermitente, su individualismo ético era inamovible"; c) La teoría de la explotación y, correlativamente, la teoría de Marx de la justicia distributiva. "Aunque la explotación no es un concepto moral fundamental, como lo sería si explotar a alguien fuera ipso facto moralmente reprobable, la teoría ofrece una sólida guía sobre lo que está bien o mal en un gran número de casos estándar... La explotación, cuando es mala, lo es no sólo por ser explotación, sino por algunos otros rasgos. En consecuencia, el concepto de explotación tiene, principalmente, una función heurística y descriptiva que en cualquier análisis real de la justicia social puede ser muy importante"; d) La teoría de Marx del cambio técnico. "Algunos de los capítulos más excitantes de El Capital $I$, son aquellos en los que Marx analiza la relación entre tecnología, beneficio, poder y derecho de propiedad a nivel de empresa"; e) La teoría de Marx de la conciencia de clase, la lucha de clases y la política. "Al nivel más general, cabría esperar que una teoría de clases ofreciera algo de carne y de sangre a la teoría abstracta de las fuerzas productivas y las relaciones de producción. Si tal era la intención de Marx, no consiguió realizarla. Esta última teoría fracasa... precisamente porque Marx no mostró cómo las clases sociales y los individuos que las forman desean vincular su destino a un nuevo ordenamiento social, sólo porque éste promete una mayor tasa de innovación"; y f) La teoría de la ideología, que debe ser resucitada. "De todas las doctrinas marxistas, ésta más que ninguna ha caído en el descrédito por los procedimientos arbitrarios adoptados. Se podría... tratar de especificar de manera verificable la idea de que la percepción de los agentes económicos de la causalidad económica depende de su localización en el sistema económico. De manera similar, algunas formas de formación caliente de ideología, tales como las preferencias motivadas por algunas teorías económicas más que por otras, no parecen estar fuera del alcance de la investigación experimental" 41.

En definitiva, para autores que como Elster se inscriben en el marxismo analítico hay aspectos importantes del pensamiento de Marx que ne- 
cesariamente tienen que ser cuestionados a fondo, pero hay también aspectos que aún poseen rigor, fuerza analítica y validez ética. Estos elementos del pensamiento de Marx que aún siguen vivos tienen que hacerse compatibles, para no perder su vitalidad y actualidad, con la teoría de la elección racional, el individualismo metodológico y la teoría de los juegos. Esto permitirá redefinir a la teoría marxista como un marxismo analítico, el cual se articulará en torno a las elecciones individuales racionales como su eje fundamental, a partir del cual las teorías de la alienación, la explotación, las contradicciones sociales, la lucha de clases y el desarrollo técnico cobrarán una nueva luz, al tiempo que se superarán el holismo metodológico, el funcionalismo y el tipo de dialéctica heredado de la tradición hegeliana. Si el marxismo es capaz de evolucionar en el sentido de convertirse en un marxismo analítico, estará encaminándose hacia el la autoerreflexión y autocrítica de sus propios supuestos teóricos, paso que es imprescindible si se quiere sacar al marxismo del atolladero teórico en que se encuentra. Si el marxismo está en crisis no habría que cerrarse a propuestas teóricas encaminadas a superar dicha crisis. Cerrarse a propuestas alternativas y, peor aún, cerrarse a planteamientos teóricos más actuales, sería renunciar a la necesaria puesta al día de un pensamiento que quizo ser, por sobre todas las cosas, científico.

Para los marxistas que todavía creen en el socialismo científico, el materialismo dialéctico, las explicaciones teleológicas y funcionales y la teoría de las fuerzas productivas-relaciones sociales de producción, las tesis del marxismo analítico seguramente generarán desconfianza y recelo, o incluso la acusación de ser la última expresión del idealismo filosófico. Sin embargo, la defensa dogmática del marxismo tradicional -constituido por los ejes arriba señalados- es lo más opuesto al espíritu cièntífico que Marx quizo imprimir a sus investigaciones. Este espíritu científico tiene que ser reivindicado ahora más que nunca si se quiere que la propuesta marxista continúe siendo atractiva. El marxismo analítico no debe ser rechazado de antemano, al igual que no debe ser asumido sin reparos, sino que debe encararse como una invitación al diálogo teórico, tan necesario en las filas marxistas, a sabiendas de que si el marxismo ha de ser aceptado como un paradigma científico su revisión permanente es necesaria, al igual que lo es su competencia con otros paragidigmas teóricos. Ese diálogo es tanto más posible en cuanto que la vitalidad del pensamiento de Marx permite que aún ahora podamos seguir comunicándonos con él. Es así como podemos concluir con el siguiente texto de Elster:

"Sobre todo, la aguda vitalidad del pensamiento de Marx hace imposible pensar que no está vivo. Su inagotable curiosidad, amplia cultura, compromiso ardiente y brillante intelecto se combinaron para crear 
una mente con la que continuamos comunicándonos través del siglo que ha transcurrido. El compromiso con fines equivocados puede resultar desastroso. Los fines Marx eran generosos y liberadores: autorrealización de los individuos, igualdad entre los individuos. Su actitud utópica y falta del control intelectual le impidieron consumar las tareas teóricas y prácticas que él mismo se había impuesto, pero sin esas cualidades ni siquiera lo hubiera intentado. El sufrió los costes, nosotros somos los beneficiarios" 42 .

\section{Referencias bibliográficas}

1. Roemer, J. E. (Comp.), El marxismo: una perspectiva analítica. México, FCE, 1989. p. 9

2. Cfr. Weinberg, J. R. Examen del positivismo lógico. Madrid, Aguilar, 1959

3. Cfr. Mardones, J. M. "El problema de Dios y la fabilidad de la razón. El racionalismo crítico de Hans Albert". En Gómez Caffarena, J., Mardones, J. M. (Coords.), Cuestiones epistemológicas. Materiales para una filosofia de la religión. I. Barcelona, Anthropos, 1992. pp. 255-277; Habermas, J., "Disputa sobre el positivismo". En La lógica de las ciencias sociales. Madrid, Tecnos, 1990. pp. 19-78

4. Popper, K., "La lógica de las ciencias sociales". En Mardones, J. M., Ursúa, N., Filosofia de las ciencias humanas y sociales. Materiales para una fundamentación científica. México, Fontamara, 1993. pp. 105-106

5. Roemer, J. E., Ibid. pp. 9-10

6. Roemer, J. E., Ibid. p. 10

7. Cfr. Elster, J., "Racionalidad, moralidad y acción colectiva". Zona Abierta, 54-55, pp. 43-68; Elster, J., "Marxismo, funcionalismo y teoría de los juegos. Alegato en favor del invidualismo metodológico". Zona Abierta, 33, pp. 21-62; Taylor, M., "Racionalidad y acción colectiva revolucionaria". Zona Abierta, 54-55, pp. 69-114; Przeworski, A., "Intereses materiales, compromisos de clase y transición al socialismo". En Roemer, J. E. (Comp.), El marxismo: una perspectiva analítica. México, FCE, 1989. pp. 188-218

8. Cfr. González, L. A., "El 'individualismo metodológico' y las modernas teorías de la elección racional". Realidad Económico-Social, V(34):431-448

9. "Presentación", Zona Abierta 54-55 (1990): 1

10. Elster, J., Una introducción a Karl Marx. México, Siglo XXI, 1992. pp. 28-29

11. Elster, J., "La posibilidad de una política racional". En Olivé, L. (Comp.), Racionalidad. Ensayos sobre la racionalidad en ética, política, ciencia y tecnología. México, Siglo XXI, 1988. p. 134

12. Ibíd. p., 24

13. Elster, J., Una instroducción a Karl Marx. México, Siglo XXI, 1991. p. 23

14. Cfr. Ibíd. p., 24

15. Ibíd.

16. Ibíd.

17. Ibíd.

18. Ibíd. p., 26 
19. Ibíd. p., 27

20. Cfr. Przeworski, A., "Marxismo y elección racional". Zona Abierta 45(1987):97

21. Elster, J., Una introducción... p., 28

22. Ibíd. p., 31

23. Ibíd. p., 32

24. Ibíd. p., 32

25. Ibíd. p., 33

26. Tbíd. p. 333

27. Para las formulaciones clásicas de la explicación funcional, Cfr. Merton, $\mathbf{R}$, Teoría y estructura sociales. México, FCE, 1964; Stinchcombe, A., Constructing social theories. Harcourt, Brace and World, 1968

28. Elster, J. Una introducción... p. 34

29. Tbíd.

30. Ibíd. p., 34

31. Ibíd.

32. Ibíd.

33. Ibíd. p., 37

34. Ibíd. p., 37

35. Ibíd. p., 38

36. Ibíd.

37. Ibíd.

38. Ibíd. pp. , 39-42

39. Ibíd. p., 195

40. Ibíd. pp. ,196-201

41. Ibíd. pp. ,194-208

42. Ibíd. p., 208 